\title{
Microsatellite and mitochondrial DNA assessment of the genetic diversity of captive Saiga antelopes (Saiga tatarica) in China
}

\author{
ZHAO ShaSha $^{1 \dagger}$, XU ChaoQun ${ }^{1 \dagger}$, LIU Gang ${ }^{1}$, LIU ShuQiang ${ }^{1}$, ZHAO ChongXue $^{2}$, \\ CUI YaXiong ${ }^{2} \& \mathrm{HU}_{\mathrm{DeFu}}{ }^{*}$ \\ ${ }^{1}$ Laboratory of Non-invasive Research Technology for Endangered Wildlife, College of Biological Sciences and Biotechnology, \\ Beijing Forestry University, Beijing 100083, China; \\ ${ }^{2}$ Gansu Endangered Animal Research Center, Wuwei 733000, China
}

Received November 20, 2012; accepted March 1, 2013; published online May 3, 2013

\begin{abstract}
To estimate the genetic diversity of the only captive Saiga antelope (Saiga tatarica) population in China, 40 umbilical cord samples were collected and mitochondrial (control region) and nuclear (microsatellite) variabilities were assessed. Both of the markers revealed low genetic variability (or high genetic homogeneity) within the population. The microsatellites yielded monitoring ranges of 2-6 alleles. The observed heterozygosities ranged from 0.28 to 0.83 , and the expected heterozygosities were between 0.27 and 0.71 . The Shannon information index (Shannon I) and Polymorphic Information Content (PIC) presented overall means of 0.87 and 0.43 , respectively. The gene diversity was 0.49 . We found only two haplotypes in the population, and the haplotype and nucleotide diversities were $39.1 \%$ and $1.13 \%$, respectively. Founder events, bottlenecks and inbreeding have contributed to the low genetic variation observed in this population. Our findings revealed the extent of genetic diversity maintained in the present population and the urgency of implementing a protection plan, introducing animals from other populations to enhance saiga's genetic variation.
\end{abstract}

Saiga tatarica, microsatellite, mitochondrial DNA, genetic diversity, bottleneck

Citation: Zhao S S, Xu C Q, Liu G, et al. Microsatellite and mitochondrial DNA assessment of the genetic diversity of captive Saiga antelopes (Saiga tatarica) in China. Chin Sci Bull, 2013, 58: 2163-2167, doi: 10.1007/s11434-013-5812-4

The Saiga antelope (Saiga tatarica) is an ungulate species living in the dry-steppe and semi-desert regions of Central Asia. It is an important economic resource and has long been hunted for its meat, hide, and especially its horns [1]. In China, saiga used to be abundant across the area of the Junggar basin and Beita Mountains. However, there has been no field record of wild saiga since the 1970s, indicating that this species has become extinct in China [2]. To prevent further population decline, saiga have been successively categorized as Critically Endangered on the Chinese Class 1 protected animal list, the Convention on International Trade in Endangered Species (CITES) Appendix II, the Convention on the Conservation of Migratory Species of

$\dagger$ These authors contributed equally to this work.

*Corresponding author (email: hudf@bjfu.edu.cn)
Wild Animals (CMS) Appendix II, and the International Union for Conservation of Nature (IUCN) Red List [1].

Moreover, in 1987 , to recover the saiga population in China, and also enable the country to become self-sufficient in saiga horn for medical use, the government launched captive breeding programs, managed by the Gansu Endangered Animal Research Center (GEARC). The captive population is descended from only nine individuals (five males, four females), which were introduced from a foreign zoo. The population recovered rapidly and, by the middle of the 1990s, their number reached 35. In 1998, the harsh winter conditions and severe disease outbreaks caused the population size to contract sharply to nine individuals, making this the most sudden and dramatic population crash in recent times. By the end of 2011 , the population of saiga at the center included 114 individuals. 
Until now, there has been no study of the population genetics of saiga in GEARC. Studies on genetic variation can help to conserve and improve an endangered species; therefore, in this study, we used two types of markers, microsatellites and mitochondrial DNA (control region), to characterize the patterns of genetic diversity in this population.

\section{Materials and methods}

\subsection{DNA extraction and PCR amplification}

Forty umbilical cord tissue samples were collected from newborn individuals at GEARC in 2011. All the samples were immediately stored on ice as soon as the female saiga delivered. Genomic DNA was extracted following the method of Sambrook et al. [3]. Extracted total genomic DNA was diluted to a final concentration of $20-40 \mathrm{ng} / \mu \mathrm{L}$ before PCR.

\subsection{Microsatellite analysis}

PCR conditions followed the method of Zhao et al. [4], with minor modifications. Amplification products were diluted $1: 10$ and microsatellite genotyping was carried out by capillary electrophoresis on an $\mathrm{ABI} 3730 \mathrm{xl}$ genetic analyzer (Applied Biosystems) with four-color fluorescently labeled primers (FAM, HEX, ROX and TAMRA).

\subsection{Microsatellite statistical analysis}

MICROCHECKER [5] was used to check the null allele. Calculation of allele frequencies, the observed and expected heterozygosity $\left(H_{\mathrm{O}}\right.$ and $\left.H_{\mathrm{E}}\right)$, numbers of alleles per locus $\left(N_{\mathrm{A}}\right)$, and exact tests for the Hardy-Weinberg equilibrium were performed using GENEPOP software [6]. POPGENE 32 Version1.31 [7] was used to calculate the Shannon I, effective allele number $\left(N_{\mathrm{E}}\right)$ and PIC. FSTAT version 2.9.3.2 [8] was used to calculate $F_{\text {IS }}$ [9] and allelic richness $\left(N_{\mathrm{R}}\right)$. Microsatellite data was used to analyze relatedness among 39 individuals by SPSS 18.0 (Figure 1). Finally, the bottleneck hypothesis was investigated using MBOTTLENECK 1.2.02 [10].

\section{4 mtDNA sequencing}

A 450 bp subsection of the mitochondrial control region was PCR amplified using primer Saiga-F (5'-CCACTATCAACACCCAAAGC-3') and primer Saiga-R (5'-GGCATTTATTGGTATGTCCTG-3'), designed from complete mtDNA sequence (GenBank accession number: JN632700.1) [11]. PCR reactions were performed in a total volume of $25 \mu \mathrm{L}$, containing $1.5 \mathrm{mmol} / \mathrm{L} \mathrm{MgCl}_{2}, 0.2 \mathrm{mmol} / \mathrm{L}$ each dNTP, $0.5 \mu \mathrm{m}$ each primer, PCR buffer and $0.3 \mu \mathrm{L}$ (2.5 units) Taq polymerase (TaKaRa). The thermal cycling program

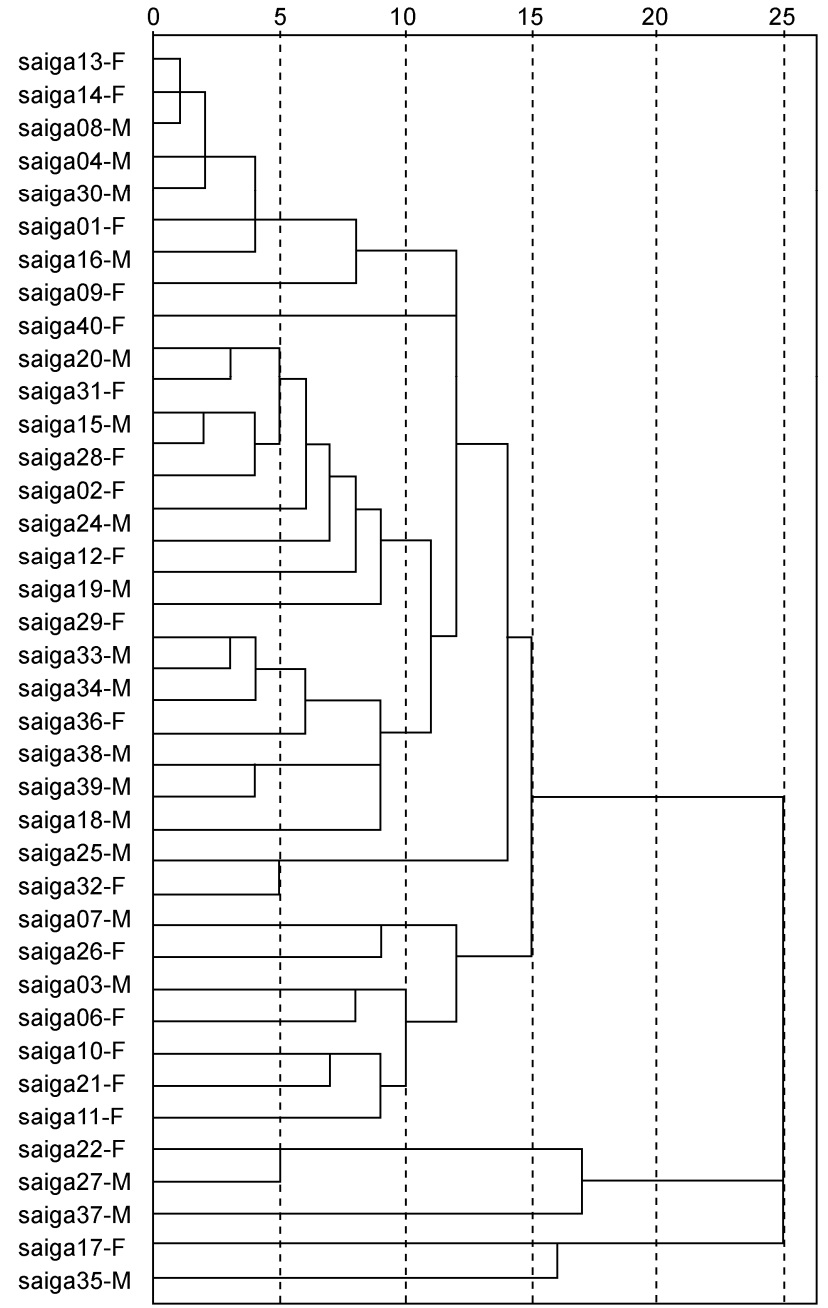

Figure 1 Genetic distance dendrogram of 39 individuals of Saiga tatarica generated by SPSS 18.0. For the $Y$-axis data, for example, "saiga14-F" means "the 14th individual of Saiga tatarica", F means female, and M means male.

consisted of pre-denaturation at $94^{\circ} \mathrm{C}$ for $10 \mathrm{~min} ; 35$ cycles of $94^{\circ} \mathrm{C}$ for $45 \mathrm{~s}, 59^{\circ} \mathrm{C}$ for $45 \mathrm{~s}$, and $72^{\circ} \mathrm{C}$ for $45 \mathrm{~s}$; followed by a final extension at $72^{\circ} \mathrm{C}$ for $10 \mathrm{~min}$. PCR products were sequenced using dye automatic-terminator sequencing with ABI PRISM 373 or 377.

\subsection{MtDNA statistical analysis}

Alignments were performed using MEGA 5.05 [12] with manual editing. Using ARLEQUIN version 3.0 [13], the number and frequency of haplotypes, polymorphic sites, transitions and transversions were calculated. Genetic diversity was measured as the number of mitochondrial haplotypes, haplotype diversity $(h)$ and nucleotide diversity $(p)$, as described by Karl [14]. The construction of Neighbourjoining tree [15] was performed using MEGA to reveal the phylogenetic relationships with saiga from Mongolia, Kalmykia and Kazakhstan, which were described by Campos et al. [16], based upon Tamura-Nei distances. 


\section{Results}

\subsection{Microsatellite data}

We tested 35 pairs of primers, many of which proved to be monomorphic: only nine pairs yielded no less than two alleles consistently. The percentage of monomorphic loci was 74.3\%. MICROCHECKER software did not detect scoring errors associated with null alleles, stuttering bands or large allele dropouts for all nine loci. Among the nine microsatellites, the number of alleles ranged from two to six alleles (Table 1), with an average of four. Microsatellites loci BM1303 and BM4621 had only two and three alleles, respectively. The observed heterozygosities ranged from 0.28 to 0.83 , and the expected heterozygosities were between 0.27 and 0.71. The Shannon I and PIC presented overall means of 0.87 and 0.43 , respectively. The gene diversity of the population was 0.49 . The allele frequencies of the microsatellite markers are given in Table 2. According to the results of the GENEPOP program, there was no significant linkage disequilibrium, indicating the independent assortment of alleles at different loci. Four of the nine loci
(BM1225, BM2113, BM4513 and BM848) significantly deviated from the Hardy-Weinberg equilibrium after Bonferroni correction. In the present study, the $F_{\text {IS }}$ value ranged from -0.35 to 0.53 , with a mean of 0.09 .

All the loci were subjected to statistical analysis using two models of microsatellite evaluation, the Infinite Alleles Model (IAM) and the Two Phase Model (TPM) to test whether the populations have undergone a recent genetic bottleneck. Most loci showed heterozygosity excess under the two models. In the Sign test conducted on all loci, the population was not found to be at mutation drift equilibrium under IAM $(P=0.0001)$ or TPM $(P=0.0016)$.

\subsection{MtDNA data}

From the 40 samples collected, the mitochondrial control region from 39 individuals was sequenced (one individual gave an unsatisfactory result). We detected 13 polymorphic sites: all of them were transitions. The haplotype diversity $(h)$ and nucleotide diversity $(p)$ were $39.1 \%$ and $1.13 \%$, respectively, which showed an extremely low level of genetic diversity. We found only two haplotypes (GenBank

Table 1 Genetic characteristics of nine microsatellite loci in the saiga population

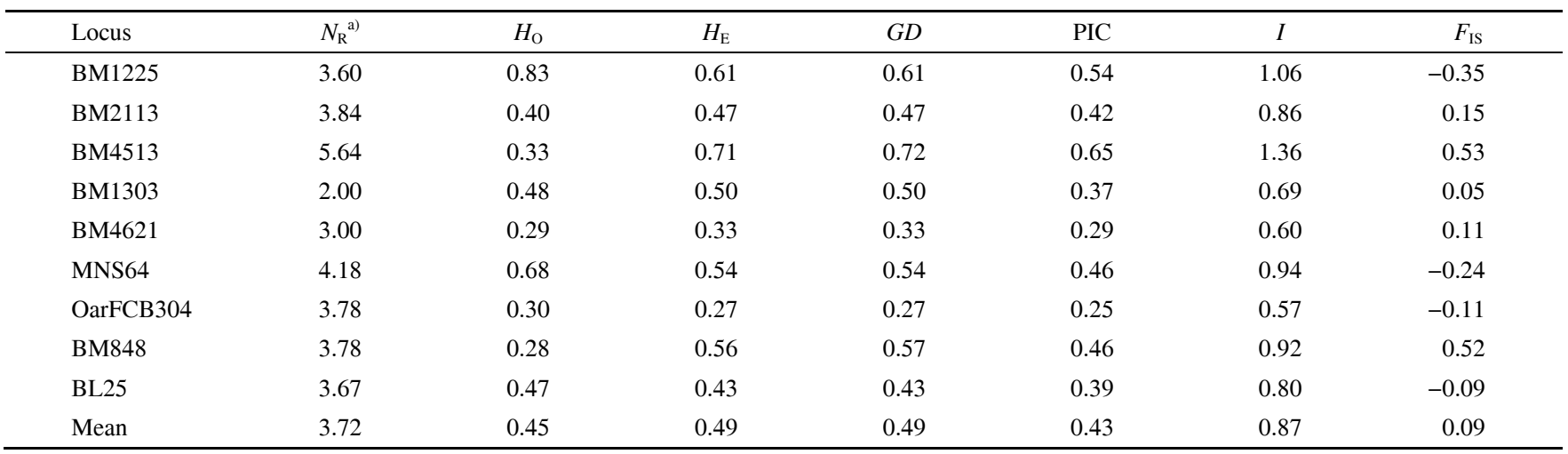

a) $N_{\mathrm{R}}$, allelic richness; $H_{\mathrm{O}}$ and $H_{\mathrm{E}}$, observed and expected heterozygosities, respectively; $G D$, gene diversity; PIC, polymorphism information content; $F_{\mathrm{IS}}$, fixation index; and $I$, Shannon information index.

Table 2 Allele frequency for different microsatellite loci in saiga

\begin{tabular}{|c|c|c|c|c|c|c|c|c|}
\hline \multirow{2}{*}{ Locus } & \multirow{2}{*}{$N_{\mathrm{A}}^{\mathrm{b})}$} & \multirow{2}{*}{$N_{\mathrm{E}}$} & \multicolumn{6}{|c|}{ Allele frequency (allele length in base pair) ${ }^{\mathrm{a})}$} \\
\hline & & & $A$ & $B$ & $C$ & $D$ & $E$ & $F$ \\
\hline BM1225 & 4.00 & 2.55 & $0.20(249)$ & $0.54(251)$ & $0.25(253)$ & $0.01(255)$ & - & - \\
\hline BM2113 & 4.00 & 1.86 & $0.20(128)$ & $0.08(134)$ & $0.70(140)$ & $0.03(142)$ & - & - \\
\hline BM4513 & 6.00 & 3.32 & $0.03(147)$ & $0.24(151)$ & $0.02(155)$ & $0.24(157)$ & $0.42(161)$ & $0.05(163)$ \\
\hline BM1303 & 2.00 & 1.97 & $0.56(150)$ & $0.44(152)$ & - & - & - & - \\
\hline MNS64 & 5.00 & 2.17 & 0.01(197) & $0.34(201)$ & $0.59(207)$ & $0.01(209)$ & $0.05(215)$ & - \\
\hline OarFCB304 & 4.00 & 1.37 & $0.85(148)$ & $0.04(154)$ & $0.09(164)$ & $0.03(182)$ & - & - \\
\hline BM848 & 4.00 & 2.26 & $0.50(230)$ & $0.44(240)$ & $0.03(258)$ & $0.04(260)$ & - & - \\
\hline BL25 & 4.00 & 1.74 & $0.11(218)$ & $0.74(220)$ & $0.01(222)$ & $0.14(224)$ & - & - \\
\hline Mean & 4.00 & 2.08 & - & - & - & - & - & - \\
\hline
\end{tabular}

a) Rare alleles are shown in bold type; b) $N_{\mathrm{A}}$, number of alleles per locus; $N_{\mathrm{E}}$, number of effective alleles. 
accession number: JQ968691-JQ968692) in this population. One haplotype was found in 29 individuals, while the other was found in the remaining 10 individuals. The average base composition of the $450 \mathrm{bp}$ fragments examined was $17.0 \%$ guanine, $29.4 \%$ adenine, $30.1 \%$ thymine, and $23.5 \%$ cytosine. We chose a $270 \mathrm{bp}$ fragment and constructed a neighbor-joining tree [15] with saiga from Mongolia, Kalmykia and Kazakhstan, which were described by Campos et al. [16], who used a 270 bp segment of the control region to investigate the genetic variation among 27 ancient and 38 modern specimens (Figure 2).

\section{Discussion}

Our result showed that the GEARC population has a low level of heterozygosity and much lower allelic diversity in nine microsatellite loci. Allelic diversity reduces faster than heterozygosity during a bottleneck [17], because the effective population size is significantly reduced, and many low frequency alleles may be eliminated, or contribute little to heterozygosity. This process could severely reduce the number of alleles by eliminating rare alleles without having a significant effect on heterozygosity [18]. After the dramatic population crash in 1998, the species experienced a genetic bottleneck, which resulted in the populations exhibiting a significant heterozygosity excess. The $N_{\mathrm{E}}$ was lower than $N_{\mathrm{A}}$, which also suggested that there are many low frequency alleles in the population (Table 2).

We also observed low genetic diversity and divergence in the mtDNA markers among the populations, which was consistent with the microsatellite results. Kholodova et al. [19-21] carried out a series of works in wild saiga based on mtDNA data during 2001-2006. They took out an approximately $450 \mathrm{bp}$ fragment of the mtDNA control region to compare the diversity of saiga from Kalmykia and Mongolia. The levels of haplotypic variation were 0.87 and 0.75 , respectively. The comparison of diversity of saiga from Kalmykia 1998-2003 and 1949-1980 suggested that 30 haplotypes had decreased to 21 haplotypes during the latest population depression. In another work, they analyzed the mtDNA control region (HV1) of 93 tissue samples from all five populations of saiga; the nucleotide diversities of Kalmykia and Mongolia were $0.031 \pm 0.006$ and $0.008 \pm 0.003$, respectively. However, the haplotype and nucleotide diversities $(h=39.1 \%, p=1.13 \%)$ in our study were lower compared with the wild populations, and were much lower than the values $(h=91.8 \%, p=3.71 \%)$ in the preliminary survey of saiga by Campos et al. [16].

Loss of genetic diversity has been considered a crucial genetic factor that tends to produce inbreeding depression, reduced adaptation and fitness, and a decrease in the longterm species survival [22-24]. The assessment of genetic diversity of populations is important for planning conservation strategies for endangered species, and it is often neces-

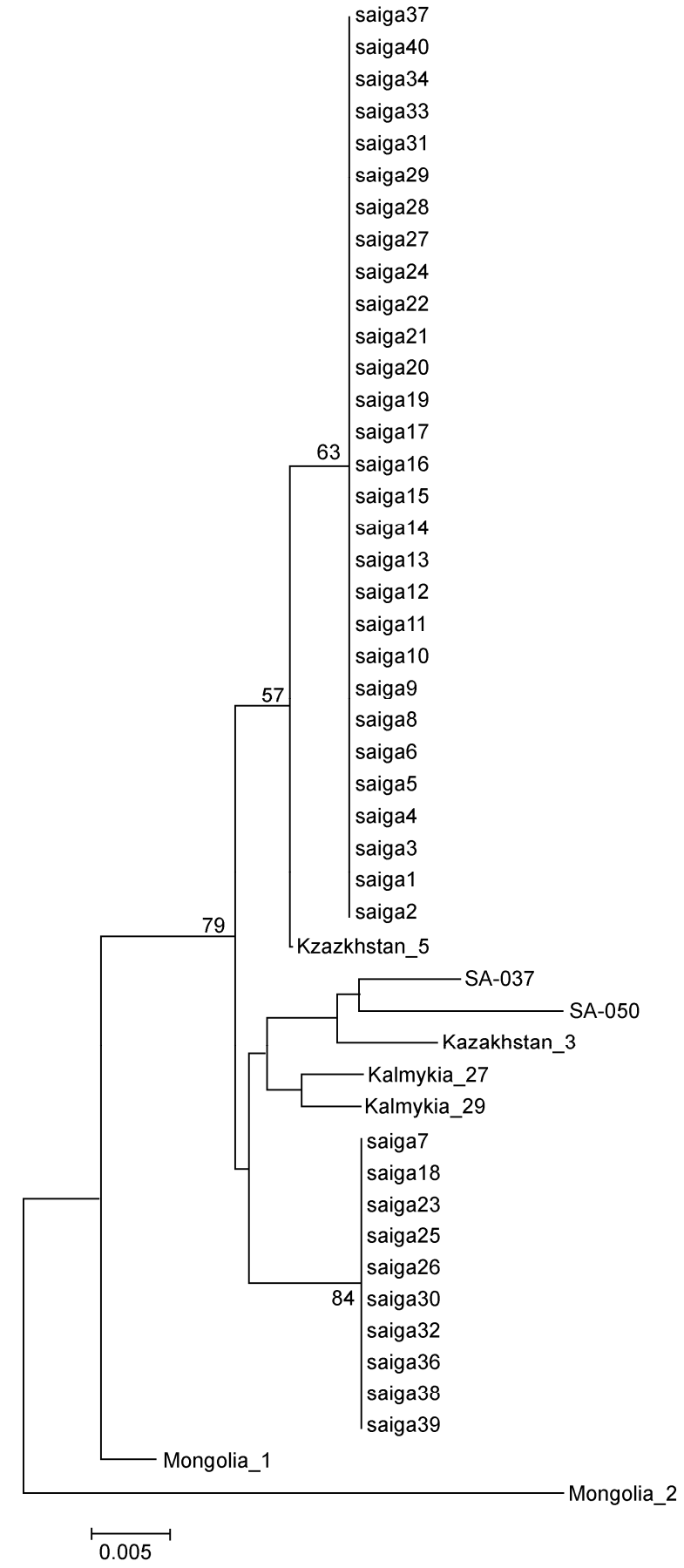

Figure 2 Neighbor-joining (NJ) tree generated by MEGA 5.05. GEARC represents the saiga population of Gansu Endangered Animal Research Center; Kazakhstan, Mongolia and Kalmykia indicate saiga from these three areas, respectively. SA represents the ancient individuals. Bootstrap values from 1000 replicates are shown when they exceed $50 \%$.

sary to investigate the causes of low levels of genetic variation in populations. The effects of genetic drift are especially important when populations are small or isolated. In fact, according to the analysis of the initiation and development of the GEARC population, both the mtDNA and microsatellite data revealed a low level of genetic variability and indicated many problems, such as founder events, bottlenecks 
and inbreeding depression in this population. Based on the neighbor-joining tree, the GEARC population forms two clades, indicating that only two female founders made genetic contributions to the current population, which occurred in isolation from populations in other areas.

When a small population reproduces, rare alleles may not be passed on to the offspring; therefore, we recommend the manager of GEARC give the individuals with the remaining rare alleles and genotypes further protection and encourage their breeding to retain a high level of genetic diversity in the future. The kinship of two individuals is directly related to inbreeding, and is represented by the inbreeding coefficient of their offspring. Although the records on parentage of the GEARC population were not kept during the early years, molecular genetic techniques can also be used to determine parentage and complete recent pedigree information. Figure 1 shows the genetic distance of 39 individuals calculated by microsatellite data. Individuals with low mean kinship have fewer relatives in the population and therefore carry fewer common alleles. Based on the current pedigree record and genetic distance of the entire GEARC population, the population can be managed as single units by choosing individuals with a more distant relationship to be parents of the subsequent generation to minimize inbreeding. In the meantime, equalizing family sizes and the sex ratio of breeders should be considered to provide optimal management of genetic diversity. When performing introduction strategies, individuals who carry unique alleles and haplotypes should be considered. Moreover, there is a potential danger of hybrid descendants; therefore, we recommend the introduction of saiga from Kazakhstan and Kalmykia populations to enrich the gene pool. The further studies such as minimizing kinship may take more microsatellite markers and long mitochondria genome segments to solve genetic problems and applying breeding and conservation strategies.

We thank GEARC for providing all the samples in this study. This work was supported by a special grant from the State Forestry Administration of China (201004054).

1 Kholodova M V, Milner-Gulland E J, Easton A J, et al. Mitochondrial DNA variation and population structure of the Critically Endangered saiga antelope Saiga tatarica. Oryx, 2006, 40: 103-107

2 Zhang X L, Bai S Y, Xu Y C. Molecular biological identification of saiga (in Chinese). J Northeast Forestry Univ, 2006, 34: 106-108

3 Sambrook J, Fritsch E F, Maniatis T. Molecular Cloning: A Laboratory Manual. 2nd ed. Cold Spring Harbor: Cold Spring Harbor Laboratory Press, 1995

4 Zhao S S, Chen X, Wan Q H. Assessment of genetic diversity in the forest musk deer (Moschus berezovskii) using microsatellite and
AFLP markers. Chin Sci Bull, 2011, 56: 2565-2569

5 Van Oosterhout C, Hutchinson W F, Wills D P M, et al. Microchecker: Software for identifying and correcting genotyping errors in microsatellite data. Mol Ecol Notes, 2004, 4: 535-538

6 Rousset F. Genepop'007: A complete re-implementation of the genepop software for Windows and Linux. Mol Ecol Res, 2008, 8: 103-106

7 Yeh F C, Francis C, Yang R C, et al. POPGENE, the user-friendly shareware for population genetic analysis. Molecular Biology and Biotechnology Centre, University of Alberta, 1997

8 Goudet J. Fstat version 1.2: A computer program to calculate Fstatistics. J Hered, 1995, 86: 485-486

9 Weir B S, Cockerham C. Estimating F-statistics for analysis of population structure. Evolution, 1984, 36: 1358-1370

10 Piry S, Luikart G, Cornuet J. MBOTTLENECK: A computer program for detecting recent reductions in the effective population size using allele frequency data. J Hered, 1999, 90: 502-503

11 Hassanin A, Delsuc F, Ropiquet A, et al. Pattern and timing of diversification of Cetartiodactyla (Mammalia, Laurasiatheria), as revealed by a comprehensive analysis of mitochondrial genomes. C R Biol, 2012, 335: 32-50

12 Tamura K, Peterson D, Peterson N, et al. MEGA 5: Molecular evolutionary genetics analysis using maximum likelihood, evolutionary distance, and maximum parsimony methods. Mol Biol Evol, 2005, 28: 2731-2739

13 Excoffier L, Laval G, Schneider S. Arlequin ver. 3.0: An integrated software package for population genetics data analysis. Evol Bioinform Online, 2005, 1: 47-50

14 Karl S A, Castro A L F, Lopez J A, et al. Phylogeography and conservation of the bull shark (Carcharhinus leucas) inferred from mitochondrial and microsatellite DNA. Conserv Genet, 2010, 12: 371382

15 Saitou N, Nei M. The neighbor-joining method: A new method for reconstructing phylogenetic trees. Mol Bio Evol, 1987, 4: 406-425

16 Campos P F, Kristensen T, Orlando L, et al. Ancient DNA sequences point to a large loss of mitochondrial genetic diversity in the saiga antelope (Saiga tatarica) since the Pleistocene. Mol Ecol, 2010, 19: 4863-4875

17 Cornuet J M, Luikart G. Description and power analysis of two tests for detecting recent population bottlenecks from allele frequency data. Genetics, 1996, 144: 2001-2014

18 Norris A T, Bradley D G, Cunningham E P. Microsatellite genetic variation between and within farmed and wild Atlantic salmon (Salmo salar) populations. Aquaculture, 1999, 180: 247-264

19 Kholodova M V, Milner-Gulland E J, Easton A J, et al. Mitochondrial DNA variation and population structure of the Critically Endangered saiga antelope Saiga tatarica. Oryx, 2006, 40: 103-107

20 Kholodova M V, Sorokin P A, Lushchekina A A. Changes in the genetic diversity of European Saiga tatarica during a drastic population depression. Doklady Biol Sci, 2005, 404: 358-359

21 Kholodova M V, Lushchekina A A, Neronov V M, et al. Comparative analysis of the Kalmyk and Mongolian Saiga genetic diversity. Doklady Biol Sci, 2001, 376: 102-104

22 Frankham R. Genetics and extinction. Biol Conserv, 2005, 126: 131140

23 Desalle R, Amato G. The expansion of conservation genetics. Nature, 2004, 5: 702-712

24 Pan H J, Shi F L, Chang Z F, et al. Mitochondrial DNA variation analysis suggests extreme low genetic diversity in Guizhou snubnosed monkeys (Thinopithecus brelichi). Chin Sci Bull, 2011, 56: 2541-2544

Open Access This article is distributed under the terms of the Creative Commons Attribution License which permits any use, distribution, and reproduction in any medium, provided the original author(s) and source are credited. 